University of Nebraska - Lincoln

DigitalCommons@University of Nebraska - Lincoln

U.S. National Park Service Publications and

Papers

National Park Service

2009

\title{
Demography and Genetic Structure of a Recovering Grizzly Bear Population
}

\author{
Katherine C. Kendall \\ USGS-NRMSC Science Center, kkendall@usgs.gov \\ Jeffrey B. Stetz \\ University of Montana, jeff.stetz@gmail.com \\ John Boulanger \\ Integrated Ecological Research, boulange@ecological.bc.ca \\ Amy MacLeod \\ University of Montana Cooperative Ecosystem Studies Unit \\ David Paetkau \\ Wildlife Genetics International \\ See next page for additional authors
}

Follow this and additional works at: https://digitalcommons.unl.edu/natlpark

Kendall, Katherine C.; Stetz, Jeffrey B.; Boulanger, John; MacLeod, Amy; Paetkau, David; and White, Gary, "Demography and Genetic Structure of a Recovering Grizzly Bear Population" (2009). U.S. National Park Service Publications and Papers. 52.

https://digitalcommons.unl.edu/natlpark/52

This Article is brought to you for free and open access by the National Park Service at DigitalCommons@University of Nebraska - Lincoln. It has been accepted for inclusion in U.S. National Park Service Publications and Papers by an authorized administrator of DigitalCommons@University of Nebraska - Lincoln. 


\section{Authors}

Katherine C. Kendall, Jeffrey B. Stetz, John Boulanger, Amy MacLeod, David Paetkau, and Gary White 


\title{
Demography and Genetic Structure of a Recovering Grizzly Bear Population
}

\author{
KATHERINE C. KENDALL, ${ }^{1}$ United States Geological Survey-Northern Rocky Mountain Science Center, Glacier Field Station, Glacier National Park, \\ West Glacier, MT 59936, USA \\ JEFFREY B. STETZ, University of Montana Cooperative Ecosystem Studies Unit, Glacier Field Station, Glacier National Park, West Glacier, MT 59936, \\ USA \\ JOHN BOULANGER, Integrated Ecological Research, 924 Innes Street, Nelson, BC V1L 5T2, Canada \\ AMY C. MACLEOD, University of Montana Cooperative Ecosystem Studies Unit, Glacier Field Station, Glacier National Park, West Glacier, MT \\ 59936, USA
}

DAVID PAETKAU, Wildlife Genetics International, Box 274, Nelson, BC V1L 5P9, Canada

GARY C. WHITE, Department of Fish, Wildife and Conservation Biology, Colorado State University, Fort Collins, CO 80523, USA

\begin{abstract}
Grizzly bears (brown bears; Ursus arctos) are imperiled in the southern extent of their range worldwide. The threatened population in northwestern Montana, USA, has been managed for recovery since 1975; yet, no rigorous data were available to monitor program success. We used data from a large noninvasive genetic sampling effort conducted in 2004 and 33 years of physical captures to assess abundance, distribution, and genetic health of this population. We combined data from our 3 sampling methods (hair trap, bear rub, and physical capture) to construct individual bear encounter histories for use in Huggins-Pledger closed mark-recapture models. Our population estimate, $\hat{N}=765$ (95\% CI $=715-831)$ was more than double the existing estimate derived from sightings of females with young. Based on our results, the estimated known, human-caused mortality rate in 2004 was $4.6 \%(95 \% \mathrm{CI}=4.2-4.9 \%)$, slightly above the $4 \%$ considered sustainable; however, the high proportion of female mortalities raises concern. We used location data from telemetry, confirmed sightings, and genetic sampling to estimate occupied habitat. We found that grizzly bears occupied $33,480 \mathrm{~km}^{2}$ in the Northern Continental Divide Ecosystem (NCDE) during 1994-2007, including 10,340 $\mathrm{km}^{2}$ beyond the Recovery Zone. We used factorial correspondence analysis to identify potential barriers to gene flow within this population. Our results suggested that genetic interchange recently increased in areas with low gene flow in the past; however, we also detected evidence of incipient fragmentation across the major transportation corridor in this ecosystem. Our results suggest that the NCDE population is faring better than previously thought, and they highlight the need for a more rigorous monitoring program. (JOURNAL OF WILDLIFE MANAGEMENT 73(1):3-17; 2009)
\end{abstract}

DOI: $10.2193 / 2008-330$

KEY WORDS abundance estimation, genetic structure, grizzly bear, mark-recapture modeling, noninvasive sampling, Northern Continental Divide Ecosystem, northwestern Montana, population monitoring, Ursus arctos.

Worldwide, large carnivores are increasingly becoming endangered (Gittleman and Gompper 2001, Cardillo et al. 2005), but efforts to detect and reverse such declines are often hampered by limited data (Gibbons 1992, Andelman and Fagan 2000). Large carnivores tend to be sparsely distributed over large areas and are difficult to observe (Schonewald-Cox et al. 1991). Grizzly bears (brown bears; Ursus arctos) exemplify these challenges and are threatened in many parts of their holarctic range.

The 5 remaining grizzly bear populations in the conterminous United States were listed as threatened in 1975 (U.S. Fish and Wildlife Service [USFWS] 1993; Fig. 1). Only 2 of these populations are currently thought to support more than approximately 50 individuals: the recently delisted population in the isolated Greater Yellowstone Ecosystem and our study population in the Northern Continental Divide Ecosystem (NCDE; Fig. 1) in northwestern Montana, USA. The NCDE population is the only large population that remains connected to Canadian populations.

The Recovery Plan for the NCDE population identifies 6 recovery thresholds related to mortality rates and distribution of breeding females (Appendix). The program is based

${ }^{1}$ E-mail: kkendall@usgs.gov on the best available science and relies on data acquired during routine agency activities rather than design-driven sampling (USFWS 1993, Vucetich et al. 2006). Multiyear counts of females with cubs are used to estimate population size and mortality rates because, in the absence of marked animals, individual females can be more easily identified than lone bears based on the number of cubs accompanying them.

Despite strong public interest and costly management programs, there has been no rigorous, ecosystem-wide assessment of distribution and abundance in the NCDE, and the status of the population was unclear. Although sightings at the edge of the population's range have increased, suggesting population growth, allowable human-caused mortality thresholds have been exceeded every year for the last decade (USFWS 1993; Appendix).

To more rigorously assess the current status of this population, we conducted intensive noninvasive genetic sampling (NGS) across all lands occupied by grizzly bears in the NCDE and augmented these data with information collected during 33 years of research and management activities. We estimated abundance, distribution, and genetic population structure using individuals identified from multilocus genotypes of hair and tissue samples collected from bears that occupied our study area during 


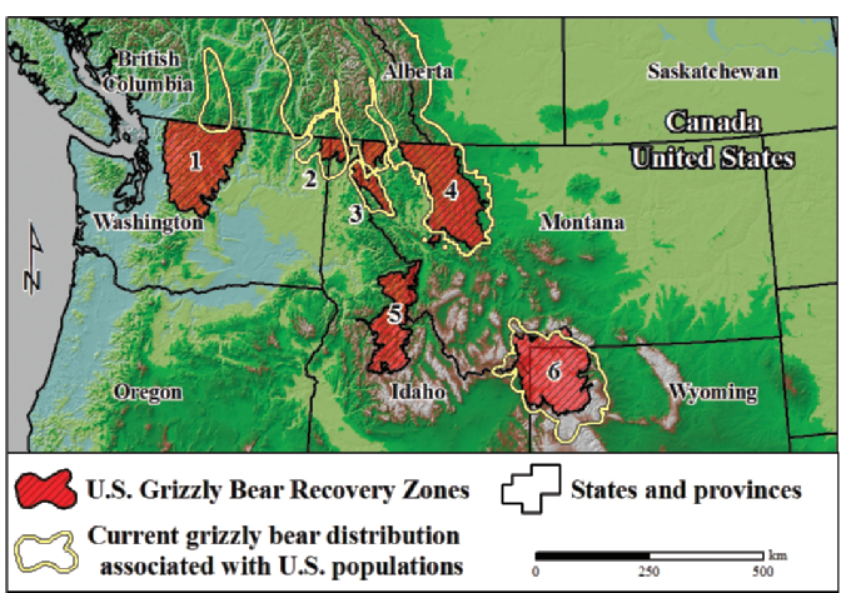

Figure 1. Location of remaining grizzly bear populations and Recovery Zones (established in the U.S. Fish and Wildlife Service [1993] Grizzly Bear Recovery Plan) south of Canada. Recovery zones: North Cascade (1), Selkirk (2), Cabinet-Yaak (3), Northern Continental Divide (4), Bitterroot (5), and Yellowstone (6).

our 2004 field season. We used our results to test assumptions about DNA-based mark-recapture analyses, estimate genetic error rates, and evaluate the USFWS program established to monitor this population.

\section{STUDY AREA}

Our $31,410-\mathrm{km}^{2}$ study area in the northern Rocky Mountains of Montana encompassed the NCDE Grizzly Bear Recovery Zone (USFWS 1993) and extended to the edge of surrounding lands thought to have grizzly bears present during our study (Fig. 2A). The only exception was along the northern edge where the study area boundary was delineated by the United States-Canada border, which was open to bear movement. Black bears (Ursus americanus) occurred throughout the NCDE. The study area had a central core of rugged mountains managed as national park, wilderness, and multiple-use forest, surrounded by lower elevation tribal, state, and corporate timber lands, state game preserves, private ranch lands, and towns. Approximately $75 \%$ of the study area was mountainous and $35 \%$ was roadless. The study area included all of Glacier National Park, portions of 5 national forests (Flathead, Kootenai, Lewis and Clark, Lolo, and Helena), 5 wilderness areas (Bob Marshall, Great Bear, Scapegoat, Mission Mountains, and Rattlesnake), parts of the Blackfeet Nation and Confederated Salish and Kootenai Indian reservations, and hundreds of private land holdings. The east-west running United States Highway 2 and Burlington Northern-Santa $\mathrm{Fe}$ (BNSF) railroad form the largest and busiest transportation corridor in the NCDE (Fig. 2).

\section{METHODS}

\section{Sampling Methods}

To maximize coverage, we used 2 independent, concurrent NGS methods to sample the NCDE grizzly bear population. Our primary effort was based on systematically distributed hair traps using a grid of $6417 \times 7-\mathrm{km}$ cells during 15 June-18 August 2004. We placed one trap in a different location in each cell during 4 14-day sampling occasions. Hair traps consisted of one 30-m length of 4prong barbed wire encircling 3-6 trees or steel posts at a height of $50 \mathrm{~cm}$ (Woods et al. 1999). We poured $3 \mathrm{~L}$ of scent lure, a 2:1 mix of aged cattle blood and liquid from decomposed fish, on forest debris piled in the center of the wire corral. We hung a cloth saturated with lure in a tree 4$5 \mathrm{~m}$ above the center of the trap. We collected hair from barbs, the ground near the wire, and the lure pile. All hairs from one set of barbs constituted a sample; we used our best judgment to define samples from the ground and lure pile. We placed each hair sample in a paper envelope labeled with a uniquely numbered barcode.

We selected hair trap locations before the field season using consistent criteria throughout the study area based on Geographic Information System (GIS) layers and expert knowledge. We based selection on evidence of bear activity, presence of natural travel routes, seasonal vegetation characteristics, and indices of recent wildfire severity. Each trap was located $\geq 1 \mathrm{~km}$ from all other hair traps, $\geq 100 \mathrm{~m}$ from maintained trails, and $\geq 500 \mathrm{~m}$ from developed areas, including campsites. To help field personnel navigate to hair traps, we loaded all coordinates into Global Positioning System (GPS) units and made custom topographic and orthophoto maps for each site.

We also collected hair during repeated visits to bear rubs during 15 June-15 September 2004. Bear rubbing was a result of natural behavior; we used no attractant. We surveyed rubs on approximately $80 \%$ of the study area; we omitted lands along the eastern edge of study area due to insufficient personnel and a relative scarcity of rubs. We identified 4 primary types of bear rubs for hair collection: trees $(85 \%)$, power poles $(8 \%)$, wooden sign and fence posts $(5 \%)$, and barbed wire fences $(2 \%)$. We focused on bear rubs located along trails, forest roads, and power and fence lines to facilitate access and ensure that we could reliably find the rubs. Each rub received a uniquely numbered tag and short pieces of barbed wire nailed to the rubbed surface in a zigzag pattern. We used barbless wire mounted vertically on bear rubs that had been bumped by horse packs. We found that the separated ends of doublestranded wire were effective at snaring hair but would not damage passing stock. During each rub visit, we collected all hair from each barb to ensure that we knew the hair deposition interval. We collected hair only from the barbed wire and passed a flame under each barb after collection to prevent contamination between sessions.

We compiled capture, telemetry, mortality, age, and past DNA detection data for 766 grizzly bears handled for research or management or identified during other hair sampling studies (Kendall et al. 2008) in the NCDE during 1975-2007. Of the bears for which tissue samples were available, 426 were successfully genotyped at $\geq 7$ loci for individual identification. We used these data 1) to identify bears that had been live-captured before 2004 for use as a covariate in mark-recapture modeling, 2) to investigate 
independence of capture probabilities among females and their dependent offspring, and 3) for our analysis of temporal trend in genetic structure. To determine the proportion of sex-age classes of bears detected with hair trap and bear rub sampling, we assumed that bears that met all of the following criteria were potentially available to be sampled: 1) $\geq 1$ location on the NCDE study area during 15 June-15 September 1995-2006, 2) alive and $\leq 20$ years old in 2004 (we included older bears if documented on the study area post-2003), and 3) not known to have died before 2004. We only included bears with reliable genotypes that were known to be present on our study area during our sampling period in our mark-recapture analysis.

\section{Genetic Methods}

We stored hair samples on silica desiccant at room temperature and blood and muscle samples either frozen or in lysis buffer. Samples were analyzed at a laboratory that specialized in low DNA quantity and quality samples, following standard protocols (Woods et al. 1999, Paetkau 2003, Roon et al. 2005). We analyzed all samples with $\geq 1$ guard hair follicle or 5 underfur hairs, and we used up to 10 guard hairs plus underfur when available.

The number and variability of the markers used to identify individuals determine the power of the multilocus genotypes to differentiate individuals. We used 7 nuclear microsatellite loci to define individuals: G10J, G1A, G10B, G1D, G10H, G10M, and G10P (Paetkau et al. 1995). Preliminary data from this population suggested that randomly drawn, unrelated individuals would have identical genotypes $\left(\mathrm{P}_{\mathrm{ID}}\right)$ with probability $1 \times 10^{-7}$, and full siblings would share identical genotypes with probability $\left(\mathrm{P}_{\mathrm{SIB}}\right) 0.0018$ for this marker set. These match probabilities assume a specified level of relationship, making it difficult to interpret them in the context of a study population in which the distribution of consanguinity is unknown. We obtained a more direct empirical estimate of match probability by extrapolating from observed mismatch distributions (Paetkau 2003). For each individual identified, we attempted to extend genotypes to 17 loci using the following markers: G10C, G10L, CXX110, CXX20, Mu50, Mu59, G10U, Mu23, G10X, and amelogenin (for gender; Ennis and Gallagher 1994).

For the first phase of the analysis, we used one microsatellite marker (G10J), which has a high success rate and at which alleles with an odd number of base pairs are diagnostic of black bears. The only exception to this rule is a 94-base pair allele that exists in both species in our ecosystem. When this allele is present, species must be confirmed through additional analyses. We set aside samples that failed at this marker twice, as well as samples with 2 odd-numbered alleles. We analyzed all individuals with $\geq 1$ 94-base pair allele at G10J at all 7 markers that we used for individual identification, whether or not the second allele was even-numbered (presumed grizzly bears) or oddnumbered (presumed black bears).

During the next phase of lab analysis, we finished individual identifications by analyzing 6 additional markers on samples that passed through the G10J prescreen. We did
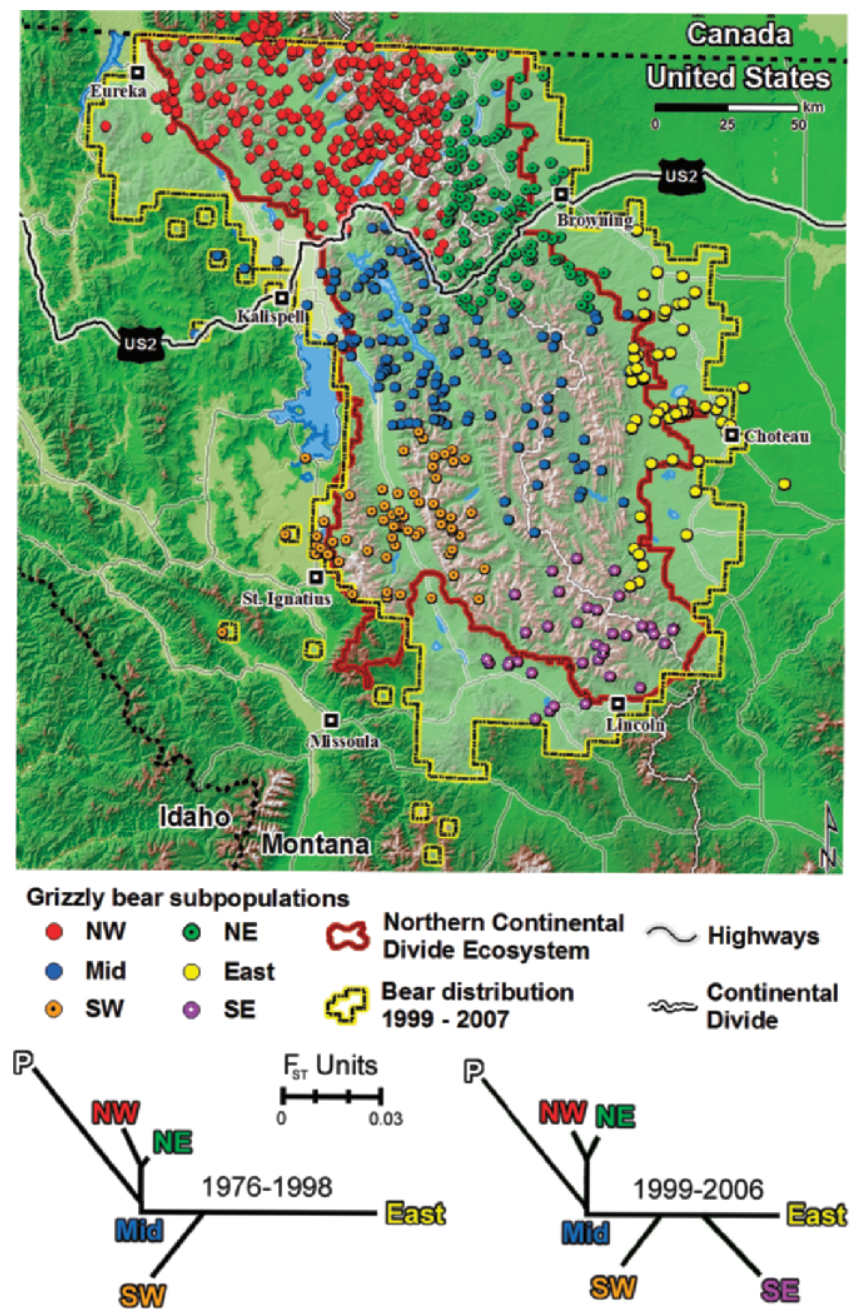

Figure 2. Change in genetic differentiation between regions within the Northern Continental Divide Ecosystem (NCDE) grizzly bear population, 1976-2006. (A) Map of region membership of grizzly bears with $\geq 13$-locus genotypes within the NCDE as grouped by factorial correspondence analysis. Distribution of grizzly bears (1994-2007) in the NCDE study area based on records of grizzly bear presence; total population range $=33,475$ $\mathrm{km}^{2}$; Grizzly Bear Recovery Zone $=23,130 \mathrm{~km}^{2}$. (B) Fitch tree of genetic distances within the NCDE population for 1976-1998 and 1999-2006. The small number of genotypes available for the SE region for 1976-1998 $(n=2)$ precluded inclusion in that time period. Genetic distance to the Prophet River (P), British Columbia, grizzly bear population $1,150 \mathrm{~km}$ north of the NCDE was included for comparison with within-NCDE population distances.

not attempt to assign individual identity to any sample that failed to produce strong, typical, diploid (i.e., not mixed) genotype profiles for all 7 markers. We believe that this strict rejection of all samples whose genotypes contained weak, missing, or suspect data (e.g., unbalanced peak heights) dramatically reduced genotyping error by eliminating the most error-prone samples.

Genotyping errors that result in the creation of false individuals, such as allelic dropout and amplification error, can bias mark-recapture population estimates (Mills et al. 2000, Roon et al. 2005). We used selective reanalysis of similar genotypes to detect and eliminate errors. We replicated genotypes for all 1) individuals identified in a 
single sample, 2) pairs of individuals that differed at only 1 or 2 loci (1- and 2-mismatch pairs), 3) pairs of individuals that differed at 3 loci when those differences were consistent with allelic dropout (i.e., homozygous), and 4) individuals with samples geographically separated by large distances (Paetkau 2003, Roon et al. 2005, Kendall et al. 2008). We further minimized the risk of undetected genotyping error by replicating genetic data for all 17 markers (including gender) in $\geq 2$ samples per individual or by repeating the analysis of all 17 markers in cases where just one sample was assigned to an individual. Whenever possible, we drew samples selected for reanalysis from a bear's 2 most distant capture points to potentially detect errors or true 0mismatch pairs. We also made a photographic record of DNA liquid transfer steps to help determine the cause of handling errors when they occurred and to resolve them.

As part of our error-checking efforts, we submitted 748 blind control samples from 32 unique grizzly bears from throughout the NCDE to the laboratory. We constructed these samples to mimic the range of DNA quantity in hair samples collected in the field by varying the number of hairs with follicles per sample. Although lab personnel were aware that control samples would be randomly scattered among field samples, they were not aware of the number or identity of control samples. Genotyped bears for which sex was known from field data provided a similar opportunity to evaluate the accuracy of gender determinations. We also submitted 115 blind test samples that we created by mixing, in various proportions, hair from 2 individuals, mostly parent-offspring or full sibling pairs. As a final overall assessment of the reliability of our data, we contracted with Dr. Pierre Taberlet (Director of Research, National Centre for Scientific Research, Grenoble, France), an expert in issues of genotyping error in noninvasive samples (Taberlet et al. 1996, Abbott 2008), to conduct an independent assessment of our field, data entry, lab, and data exchange protocols. Among other tests, P. Taberlet examined the results of 100 randomly drawn and 406 blind samples for errors and then checked whether the data from the genetic analysis matched the database used for abundance estimates.

We replicated almost every genotype in the 17-locus data set, either between samples, by repeated analysis as positive controls, or during error-checking, which provided an outstanding opportunity to detect genotyping errors. We recorded an error each time a genotype was changed after being entered into the database as a high-confidence score (i.e., not flagged as requiring reanalysis to confirm a weak initial result). The extra measures we used to avoid the creation of spurious individuals, along with our large sample size, permitted us to evaluate the standard methods that formed the foundation of our genotyping protocol (Paetkau 2003). Before starting the analysis of supplemental markers (in duplicate, with emphasis on geographically distant samples), we generated a preliminary 7-locus results file using only the standard protocol of selective reanalysis of similar genotypes.

\section{Estimating Abundance, Mortality, Distribution, and Genetic Population Structure}

We developed an approach to abundance estimation that combined data from our 3 sampling methods (hair trap, bear rub, and physical capture) to construct individual bear encounter histories for use in Huggins-Pledger closed mark-recapture models (Huggins 1991, White and Burnham 1999, Pledger 2000, Boulanger et al. 2008a, Kendall et al. 2008). We performed all mark-recapture analyses in Program MARK (White and Burnham 1999; Pledger model updated May 2007). The Huggins model allows the use of individual covariates, in addition to group and temporal covariates, to model capture probability heterogeneity. Pledger (2000) mixture models use $\geq 2$ capture probabilities to model heterogeneity by partitioning animals into groups with relatively homogenous capture probabilities. Our candidate models included gender, bear rub sampling effort (RSE), history of previous live capture (PrevCap), and distance to edge (DTE) covariates. Rub sampling effort was the number of days since the last survey summed for all bear rubs surveyed in a session. We considered a bear to have a history of live capture if it had been captured or handled, regardless of method, at any time before or during hair trap sampling. Distance to edge was the distance of the average capture location of each bear from the open (northern) boundary.

We used a stepwise a priori approach to mark-recapture model development. To determine the best structure for each data type, we initially modeled hair trap and bear rub data separately. We pooled the other 2 data types and used them as the first sample occasion for each exercise. For example, in the hair trap models, we combined bear rub and physical capture detections as the first sample session followed by the 4 hair trap sessions. We then combined the most supported hair trap and bear rub models into a single analysis in which we constructed encounter histories for each of the 563 bears detected during 10 sampling occasions as follows: physical capture (1), detection during 4 hair trap sessions (2-5), and detection during 5 bear rub survey sessions (6-10).

We evaluated relative support for candidate models with the sample size-adjusted Akaike Information Criterion for small sample sizes $\left(\mathrm{AIC}_{c}\right)$. We obtained estimates of population size as a derived parameter of Huggins-Pledger closed mixture models in Program MARK (White and Burnham 1999, White et al. 2001). Calculation of $95 \% \log -$ based confidence intervals about those estimates incorporated the minimum number of bears known to be alive on the study area (White et al. 2001). We averaged population estimates based on their support in the data, as indexed by $\mathrm{AIC}_{c}$ weights, to account for model selection uncertainty (Burnham and Anderson 2002).

We used our abundance estimate to calculate an estimate of the known, human-caused mortality rate in 2004 for comparison with mortality and abundance estimates generated using the Recovery Plan method (USFWS 1993). The Recovery Plan population estimate and the number of 
mortalities applied only to the Recovery Zone plus a 16.1$\mathrm{km}$ buffer. Because our abundance estimate covered a larger area, we used the total number of mortalities for this area to calculate mortality rate.

To determine the current range of grizzly bears, we plotted confirmed records of grizzly bear presence from hair snaring, captures, telemetry, mortalities, and sightings from 1994 to 2007 on a $5-\mathrm{km}$ grid. We defined the edge of current distribution as the outermost occupied cells adjacent to other occupied cells. We mapped an occupied cell as an outlier if it was separated from other cells with bears by $>1$ empty cell (Fig. 2A).

To investigate population genetic structure, we identified regional subpopulation boundaries using factorial correspondence analysis (FCA) conducted in GENETIX (Belkhir et al. 2004). We adjusted the number and location of geographic boundaries on an ad hoc basis to minimize overlap of geographically defined genetic clusters (Fig. 2A). We used $F_{S T}$ (Weir and Cockerham 1984, Barluenga et al. 2006) to estimate genetic differentiation between regions and visualized these values with Fitch trees (Fitch and Margoliash 1967). To determine gene flow across United States Highway 2 and BNSF railroad, we divided the corridor into 3 segments and used assignment tests (Paetkau et al. 1995) to compare the 50 individuals nearest to the highway on either side of the western and eastern sections (data not shown for the middle section; Fig. 2A).

To examine change in genetic structure over time, we divided our data set into 347 animals first captured before 1999 and 600 animals first captured more recently. We based the choice of 1998 as the cut-off for the earlier period on available sample size, which increased considerably after 1998. We conducted all population genetics analyses using $\geq 13$-locus genotypes. We used 15 of the 16 microsatellite markers used in the NCDE in the data sets for bear populations in Canada and Alaska to which we made comparisons of genetic variability and population structure. Genetic distance calculations between the Prophet River and NCDE populations used 15-locus genotypes provided by G. Mowat (British Columbia Ministry of Environment, Nelson, BC, Canada; Poole et al. 2001).

\section{RESULTS}

\section{Sampling Effort}

From 15 June to 18 August 2004, we collected 20,785 bear hair samples from 2,558 scent-baited hair traps (Fig. 3A; Table 1). We also collected 12,956 hair samples from 4,795 bear rubs (Fig. 3B; Table 2). We conducted 18,021 rub visits during our 15 June-15 September 2004 field season, for an average of 3.8 visits/rub ( $\mathrm{SD}=1.04$; range $1-7$; Table 2).

Genotyping Success, Marker Power, and Quality Control We culled many of the 33,741 hair samples collected from hair traps and bear rubs before the first stage of analysis based on inadequate number of follicles $(26.4 \%)$, obvious non-grizzly bear origin $(2.3 \%)$, and subsampling criteria $(2.1 \%)$. We attempted to genotype $23,325(69.1 \%)$ samples. Genotyping success exceeded $70 \%$ with $\geq 3$ guard hairs or
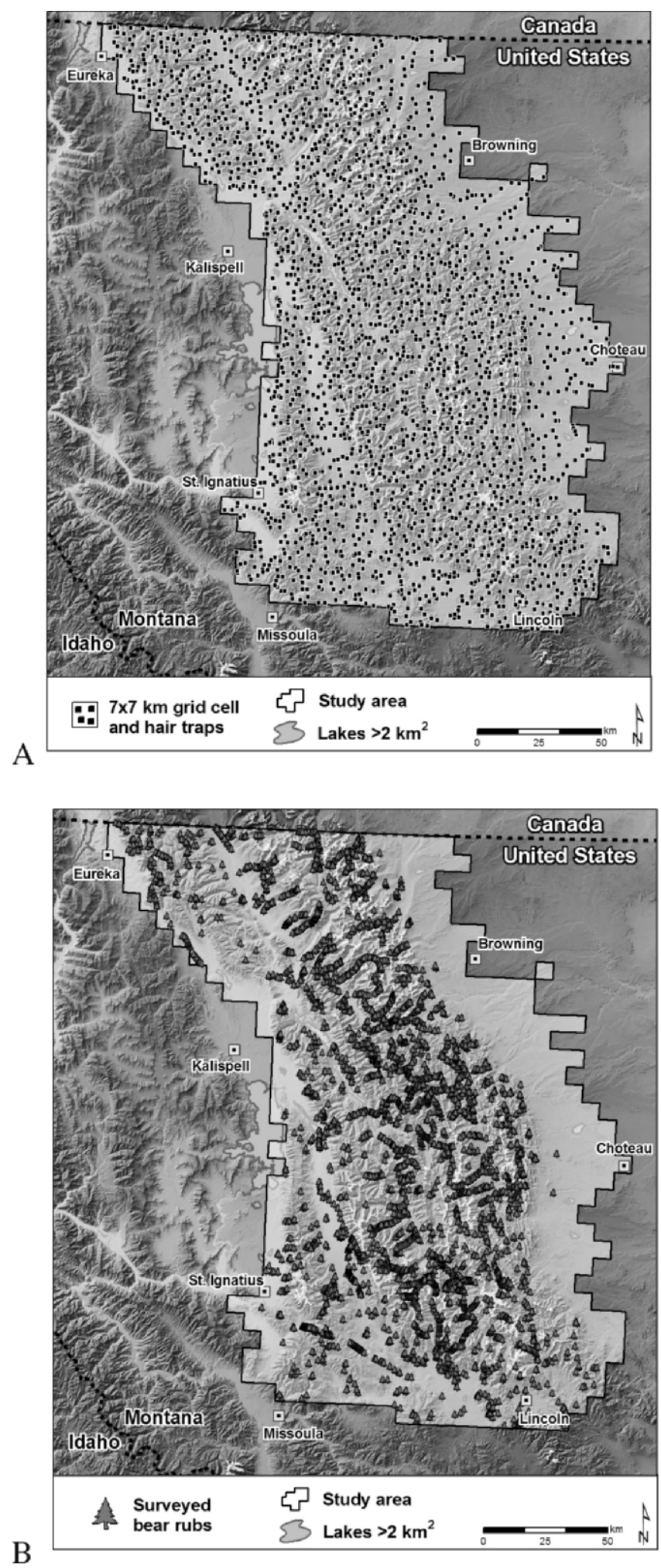

Figure 3. Location of grizzly bear hair snaring sites in the Northern Continental Divide Ecosystem, Montana, USA. (A) Location of bear hair traps $(n=2,558)$. We conducted hair trap sampling 15 June-18 August 2004. (B) Location of bear rubs $(n=4,795)$. We surveyed bear rubs on trails, forest roads, and power and fence lines during 15 June-15 September 2004.

$\geq 11$ underfur follicles; success rates were similar for samples from hair traps and bear rubs. Of the samples we screened with the G10J marker, we set aside $17.3 \%$ after they failed twice and $51.2 \%$ identified as black bear (with 2 odd- 
Table 1. Grizzly bear hair trap results. We conducted hair trapping 15 June 2004-18 August 2004 in the Northern Continental Divide Ecosystem in northwestern Montana, USA, for 4 14-day sessions. ${ }^{a}$

\begin{tabular}{|c|c|c|c|c|c|c|c|c|c|}
\hline \multirow[b]{2}{*}{ Session } & \multirow[b]{2}{*}{ No. sites } & \multirow{2}{*}{$\begin{array}{c}\% \text { traps with } \geq 1 \\
\text { grizzly bear sample }\end{array}$} & \multicolumn{2}{|c|}{ Grizzly bear samples/trap ${ }^{b}$} & \multirow{2}{*}{$\begin{array}{c}\text { Total no. } \\
\text { grizzly bear samples }\end{array}$} & \multicolumn{2}{|c|}{ No. new bears } & \multicolumn{2}{|c|}{ No. unique bears } \\
\hline & & & $\bar{x}$ & SD & & $\mathbf{F}$ & $\mathbf{M}$ & $\mathbf{F}$ & $\mathbf{M}$ \\
\hline 1 & 640 & 19.4 & 4.3 & 4.0 & 535 & 70 & 60 & 70 & 60 \\
\hline 2 & 637 & 15.5 & 5.8 & 6.4 & 570 & 44 & 40 & 50 & 55 \\
\hline 3 & 638 & 20.2 & 6.2 & 6.8 & 796 & 83 & 39 & 111 & 55 \\
\hline 4 & 643 & 19.7 & 6.4 & 6.8 & 810 & 69 & 43 & 114 & 76 \\
\hline $\bar{x}$ & 640 & 18.7 & 5.7 & 6.0 & 678 & 67 & 46 & 86 & 62 \\
\hline Total & 2,558 & & & & 2,711 & & & 266 & 182 \\
\hline
\end{tabular}

${ }^{\mathrm{a}} \bar{x}=13.98$ days, $\mathrm{SD}=1.27$.

${ }^{\mathrm{b}}$ Of those hair traps that had $\geq 1$ grizzly bear hair sample.

numbered alleles). We obtained complete 7-locus genotypes for $74.2 \%(n=4,218)$ of the samples that passed the G10J prescreen. We encountered samples with hair from $>1$ bear infrequently; we classified $0.4 \%$ of hair trap and $0.8 \%$ of bear rub samples as mixed based on the appearance of $\geq 3$ alleles at $\geq 3$ markers. Of the 563 individual grizzly bears we used in our analyses, 560 had complete genotypes at 17 microsatellite loci and 542 were fully replicated at all 17 markers with $\geq 2$ independent, high-confidence genotypes.

Mean observed heterozygosity across the 7 markers used to identify individuals was 0.73 (Table 3). The probability that 2 randomly drawn, unrelated individuals would share the same genotype $\left(\mathrm{P}_{\mathrm{ID}}\right)$ was $9 \times 10^{-8}$, and the probability that full siblings would have identical genotypes $\left(\mathrm{P}_{\mathrm{SIB}}\right)$ was 0.0017. Extrapolation from the mismatch distribution in our data set suggested approximately one pair of individuals with identical 7-locus genotypes. Expressed as a match probability, this equates to approximately $1 / 158,203$, or $6 \times$ $10^{-6}$, midway between the estimates for siblings and unrelated bears (based on $563 \times 562 / 2=158,203$ pairs of individuals in the data set, and a predicted one pair of individuals with the same 7-locus genotype).

When we considered all available markers, all individual bears differed at $\geq 3$ loci. All 563 individuals identified by the original 7-locus analysis also had unique multilocus genotypes for the supplemental microsatellite markers. Given the low rate of genotyping error documented during data duplication (above) and by blind control samples (below) there was effectively zero probability that a pair of samples from a given individual would contain undetected genotyping errors in both the original 7-locus and supplemental 9-locus genotype, so errors in the first 7 markers would be detected by discovery of matching genotypes at the supplemental markers.

As expected, some of the 748 blind control samples were of inadequate quality to obtain a reliable genotype. However, $100 \%$ of the 653 samples that we successfully genotyped were assigned to the correct individual, giving an estimated error rate for 7 -locus genotypes of $<1 / 653$ (0.0015). As argued above, we believe that the actual number of false individuals is zero, but the blind controls provide an upper bound on the rate of error. Gender matched in all 514 cases for which we knew sex from field data. All of 115 deliberately mixed samples from 2 individuals were either assigned a genotype that matched 1 of the 2 source bears, failed to produce a clear genotype, or were correctly identified as mixed. In no case was a spurious individual recognized through mixing of alleles from 2 individuals' genotypes, presumably because of the strict exclusion of samples with atypical genotype profiles at even one marker. The independent assessment of field and laboratory protocols concluded that 1) all consistency checks strongly supported the reliability of the data, 2) no mechanism for systematic error was present, and 3) the error rate for the number of individual bears identified was $\leq 1 \%$.

Factorial correspondence analysis (Kadwell et al. 2001, Belkhir et al. 2004) based on 6-locus genotypes (i.e., excluding G10J) provided unambiguous and independent

Table 2. Grizzly bear rub survey results. We conducted surveys 15 June 2004-15 September 2004 in the Northern Continental Divide Ecosystem in northwestern Montana, USA. We combined sessions with low sampling effort for mark-recapture analysis.

\begin{tabular}{|c|c|c|c|c|c|c|c|c|c|c|}
\hline \multirow[b]{2}{*}{ Session } & \multirow{2}{*}{$\begin{array}{l}\text { No. bear } \\
\text { rub visits }\end{array}$} & \multirow{2}{*}{$\begin{array}{l}\% \text { bear rubs with } \\
\text { grizzly bear hair }\end{array}$} & \multicolumn{2}{|c|}{ No. grizzly bear samples/rub ${ }^{\mathbf{a}}$} & \multirow{2}{*}{$\begin{array}{l}\text { Rub tree } \\
\text { effort }^{\text {b }}\end{array}$} & \multirow{2}{*}{$\begin{array}{c}\text { Total no. } \\
\text { grizzly bear samples }\end{array}$} & \multicolumn{2}{|c|}{ No. new bears } & \multicolumn{2}{|c|}{ No. unique bears } \\
\hline & & & $\bar{x}$ & SD & & & $\mathbf{F}$ & $\mathbf{M}$ & $\mathbf{F}$ & $\mathbf{M}$ \\
\hline $1-2$ & 3,186 & 18.7 & 2.5 & 1.8 & 53,220 & 595 & 17 & 68 & 17 & 68 \\
\hline 3 & 3,510 & 13.8 & 2.4 & 1.8 & 61,900 & 484 & 29 & 34 & 32 & 68 \\
\hline 4 & 3,081 & 13.2 & 2.6 & 2.1 & 57,001 & 406 & 24 & 20 & 33 & 50 \\
\hline 5 & 4,208 & 11.7 & 2.3 & 1.6 & 82,358 & 494 & 35 & 22 & 54 & 63 \\
\hline$>6$ & 4,036 & 10.4 & 2.2 & 1.5 & 63,999 & 380 & 15 & 11 & 39 & 50 \\
\hline $\bar{x}$ & 3,604 & 13.6 & 2.4 & 1.8 & 63,696 & 472 & 24 & 31 & 35 & 60 \\
\hline Total & 18,021 & & & & 318,478 & 2,359 & & & 120 & 155 \\
\hline
\end{tabular}

\footnotetext{
${ }^{a}$ Of those bear rub visits that had at least one grizzly bear hair sample.

${ }^{\mathrm{b}}$ Rub sampling effort (RSE) is the cumulative no. of days between successive hair collections for each rub sampled per session. For example, if we surveyed 3,000 rubs during session 3, each surveyed 20 days earlier, the RSE for session 3 would be $3,000 \times 20=60,000$.
} 
Table 3. Variability of microsatellite markers used to determine individual identity of grizzly bears in the Northern Continental Divide Ecosystem in northwestern Montana, USA, in 2004. ${ }^{\mathrm{a}}$

\begin{tabular}{lccccc}
\hline \multicolumn{1}{c}{ Marker } & $\boldsymbol{H}_{\boldsymbol{E}}$ & $\boldsymbol{H}_{\boldsymbol{O}}$ & $\mathrm{A}$ & $\mathbf{P}_{\mathbf{I D}}$ & $\mathbf{P}_{\text {SIB }}$ \\
\hline G10J & 0.76 & 0.72 & 6 & 0.10 & 0.40 \\
G1A & 0.72 & 0.73 & 7 & 0.11 & 0.42 \\
G10B & 0.77 & 0.74 & 9 & 0.08 & 0.38 \\
G1D & 0.79 & 0.80 & 11 & 0.07 & 0.37 \\
G10H & 0.68 & 0.65 & 11 & 0.13 & 0.44 \\
G10M & 0.71 & 0.69 & 9 & 0.14 & 0.43 \\
G10P & 0.77 & 0.75 & 7 & 0.08 & 0.39 \\
$\bar{x}$ & 0.74 & 0.73 & 8.6 & & \\
$\begin{array}{l}\text { Overall probability } \\
\text { of identity }\end{array}$ & & & & $9 \mathrm{E}-08$ & 0.0017 \\
\hline
\end{tabular}

${ }^{a} H_{E}=$ expected heterozygosity; $H_{O}=$ observed heterozygosity; $\mathrm{A}=$ no. of alleles; $\mathrm{P}_{\mathrm{ID}}=$ probability of identity; $\mathrm{P}_{\mathrm{SIB}}=$ probability of sibling identity.

species assignment for all individuals and confirmed that all individuals with $\geq 1$ odd-numbered allele were black bears. The black bear genotypes that were closest to grizzly bears in the FCA had their genotypes extended to 16 microsatellite markers, as did genotypes that were homozygous for allele 94 at G10J. Subsequent 15-locus FCA analysis (excluding G10J) confirmed earlier 6-locus species assignments and identified 58 grizzly bears and 2 black bears that were homozygous for allele 94 .

We estimated our rates of initial error (i.e., before errorchecking) were 0.005 per locus per sample for the 7 microsatellites used on all samples, 0.002 for the 9 extra microsatellite markers, and 0.0007 for gender. Overall, we classified $67 \%$ of the 234 detected errors as human errors (e.g., inaccurate scoring), $18 \%$ as allelic dropout, and $15 \%$ as false or irreproducible amplifications.

\section{Population Abundance, Mortality, Distribution, and Genetic Structure}

Our model-averaged abundance estimate for the NCDE population in 2004 was $\hat{N}=765(95 \%$ CI $=715-831$; Table 4). Although this represents a superpopulation estimate (Crosbie and Manly 1985), we estimated from radiotelemetry and DNA captures that only $0.5 \%$ of the bears we sampled moved outside of the study area to the west or east, and $1 \%$ of bears crossed the northern boundary of our study area (12\% of the perimeter) during our 2004 sample period. Total known, human-caused mortality when calculated using our abundance estimate was $4.6 \%(95 \%$ $\mathrm{CI}=4.2-4.9 \%$ ); the female mortality rate was double the maximum allowed by the Recovery Plan (Appendix; USFWS 1993).

Our data supported 10 models as indicated by $\Delta \mathrm{AIC}_{c}$ values $\leq 2$ (Burnham and Anderson 2002; Table 5). However, our stepwise model development process resulted in very similar candidate models in the final stages of the analysis. In fact, the only parameters that varied were the sex-specific DTE threshold values. Our joint (physical capture-hair trap-bear rub) models suggested that hair trap capture probabilities mainly varied by sex, time, and PrevCap (Table 5). Average per-session capture probabilities were similar across genders for hair traps $\left(\hat{\bar{p}}_{\mathrm{M}}=0.22\right.$;
Table 4. Total minimum counts and model-averaged estimates of grizzly bear population abundance in the Northern Continental Divide Ecosystem in northwestern Montana, USA, in 2004.

\begin{tabular}{|c|c|c|c|c|c|c|}
\hline \multirow[b]{2}{*}{ Parameter } & \multirow{2}{*}{$\begin{array}{l}\text { Min. } \\
\text { count }\end{array}$} & \multirow[b]{2}{*}{ Estimate } & \multirow[b]{2}{*}{ SE } & \multirow{2}{*}{$\begin{array}{l}\text { CV } \\
(\%)\end{array}$} & \multicolumn{2}{|c|}{$95 \%$ log-based CI } \\
\hline & & & & & Lower & Upper \\
\hline M & 242 & 294.58 & 12.01 & 4.1 & 276 & 324 \\
\hline $\mathrm{F}$ & 321 & 470.60 & 26.16 & 5.6 & 427 & 531 \\
\hline Pooled & 563 & 765.18 & 29.27 & 3.8 & 715 & 831 \\
\hline
\end{tabular}

$\left.\hat{\bar{p}}_{\mathrm{F}}=0.19\right)$, with both genders having the lowest capture probabilities in session 2 and the highest by session 4 (Fig. 4). Bears with a history of previous live capture were $58.4 \%$ $(95 \% \mathrm{CI}=42-79 \%)$ less likely to be captured in hair traps than were bears with no known record of capture. Bear rub capture probabilities varied by sex, sex-specific temporal trends, and RSE (Table 5). Males had approximately 3-fold higher average capture probabilities than females, but males displayed slightly declining capture probabilities over time. Conversely, females showed a slight increasing trend in capture probabilities over time and were nearly equal with males in session 4 (Fig. 4). In addition, there was undefined heterogeneity present in the bear rub data as indicated by the support for mixture models with this data type (Table 5). The DTE threshold values for the most supported model was $\leq 15 \mathrm{~km}$ and $5 \mathrm{~km}$ for males and females, respectively, which is consistent with bear biology because males are expected to move greater distances than females. Generally, as DTE increased above those levels, model support declined (Table 5).

Spring molting and behavioral differences between males and females could cause variation in hair deposition rates, sometimes in opposing directions. Because this may have influenced DNA capture probabilities, we examined our data for seasonal and gender-based differences in the number of hair samples deposited. Our data showed no seasonal trend in the number of hair samples left by females and a slight decrease in the number of samples deposited by males over the course of hair sampling. Although male and female hair deposition rates differed by sampling type (hair trap or bear rubs), this did not result in variable detection rates because we needed only one sample from each individual per hair sampling site to document presence.

In total, we detected 545 unique bears with our joint hair snaring methods, or $71 \%$ of the estimated population. By comparing hair snaring captures to genotypes from 276 handled bears of known sex and age class, we estimated hair snaring detected $44 \%$ of cubs, $80 \%$ of yearlings, and $89 \%$ of adult females known to be, or potentially present (Table 6). From our live-captured bear data, we knew of 6 family groups detected at hair traps. Of the 17 instances when we detected one member of a family group, we failed to detect other family members $53 \%$ of the time. Bear rub data also showed variable detection within families; we detected multiple members of the same group together in only $31 \%$ of 16 opportunities.

We detected 321 unique females and estimated there were 
Table 5. Model selection results from mark-recapture analysis of the grizzly bear population in the Northern Continental Divide Ecosystem in northwestern Montana, USA, in 2004, sampled using physical capture (occasion 1), hair traps (occasions 2-5), and bear rubs (occasions 6-10). We present only models with $\Delta \mathrm{AIC}_{c}<2$. Results from Program MARK, 25 November 2007 build.

\begin{tabular}{|c|c|c|c|c|c|c|}
\hline Model $^{\mathrm{a}}$ & $\mathrm{AIC}_{c}^{\mathrm{b}}$ & $\Delta \mathrm{AIC}_{c}^{\mathrm{c}}$ & $w_{i}^{\mathrm{d}}$ & Model likelihood & No. parameters & Deviance \\
\hline Base model + DTE $_{\mathrm{M} 15 \mathrm{~km}}, \mathrm{DTE}_{\mathrm{F} 5 \mathrm{~km}}$ & $5,012.216$ & 0 & 0.116 & 1 & 21 & $4,970.051$ \\
\hline Base model + DTE $_{5 \mathrm{~km}}$ & $5,012.624$ & 0.409 & 0.094 & 0.815 & 20 & $4,972.474$ \\
\hline Base model + DTE $_{\mathrm{M} 20 \mathrm{~km}}, \mathrm{DTE}_{\mathrm{F} 5 \mathrm{~km}}$ & $5,012.894$ & 0.678 & 0.082 & 0.712 & 21 & $4,970.729$ \\
\hline Base model + DTE $_{15 \mathrm{~km}}$ & $5,012.947$ & 0.731 & 0.080 & 0.694 & 20 & $4,972.797$ \\
\hline Base model + DTE $_{M 25 \mathrm{~km}}, \mathrm{DTE}_{\mathrm{F} 5 \mathrm{~km}}$ & $5,013.084$ & 0.868 & 0.075 & 0.648 & 21 & $4,970.919$ \\
\hline Base model + DTE $_{10 \mathrm{~km}}$ & $5,013.117$ & 0.902 & 0.074 & 0.637 & 20 & $4,972.968$ \\
\hline Base model + DTE $_{\mathrm{M} 15 \mathrm{~km}}$, DTE $_{\mathrm{F} 10 \mathrm{~km}}$ & $5,013.132$ & 0.917 & 0.073 & 0.632 & 21 & $4,970.967$ \\
\hline Base model $+\mathrm{DTE}_{\mathrm{M} 30 \mathrm{~km}}, \mathrm{DTE}_{\mathrm{F} 5 \mathrm{~km}}$ & $5,013.496$ & 1.280 & 0.061 & 0.527 & 21 & $4,971.331$ \\
\hline Base model $+\mathrm{DTE}_{\mathrm{M} 20 \mathrm{~km}}, \mathrm{DTE}_{\mathrm{F} 10 \mathrm{~km}}$ & $5,013.806$ & 1.590 & 0.052 & 0.452 & 21 & $4,971.641$ \\
\hline Base model + DTE $_{\mathrm{M} 10 \mathrm{~km}}, \mathrm{DTE}_{\mathrm{F} 5 \mathrm{~km}}$ & $5,013.899$ & 1.684 & 0.050 & 0.431 & 21 & $4,971.735$ \\
\hline
\end{tabular}

${ }^{a}$ Base model notation: PC (.) [HT: $\mathrm{p}\left(\operatorname{sex} \times \mathrm{t}+\right.$ PrevCap) RT: $\left.\pi(\operatorname{sex}) \mathrm{p}_{1 \& 2}(\times \operatorname{sex}+\operatorname{sex} \times \mathrm{T}+\mathrm{RSE})\right]$. Base model description: Physical capture probability held constant. Hair trap: sex- and session-specific capture probabilities (p), with an effect of previous live capture (PrevCap), i.e., known to have a previous physical capture. Rub tree: sex-specific mixture probability $(\pi)$. Capture probability is sex-specific with sex-specific linear trends $(\mathrm{T})$, and an effect of rub sampling effort. Parameter definitions: $\mathrm{PC}=$ physical capture; $\mathrm{HT}=$ hair trap; $\mathrm{RT}=$ rub tree (includes all types of bear rubs). Mixture models only supported for RT data. RSE = rub sampling effort: cumulative no. of days between successive hair collections across all sampled rubs/session. For example, if we surveyed 2,000 rubs during session 2, each surveyed 20 days earlier, the RSE for session 2 would be 2,000 $\times 20=40,000$. DTE $=$ individual covariate of distance to northern edge of study area. Effects of distance to edge are limited to the thresholds specified in model notation, e.g., DTE $\mathrm{M}_{\mathrm{M} 15 \mathrm{~km}}$ means that only male bears with an average capture location $\leq 15 \mathrm{~km}$ from the northern edge are modeled with this covariate.

${ }^{b}$ Akaike's Information Criterion for small sample sizes.

${ }^{c}$ The difference in $\mathrm{AIC}_{c}$ value between the $i$ th model and the model with the lowest $\mathrm{AIC}_{c}$ value.

$\mathrm{d}$ Akaike wt used in model averaging.

$470(95 \% \mathrm{CI}=427-531)$ in the NCDE population. We detected $\geq 1$ (range 2-56) female in each of the 23 Bear Management Units defined in the Recovery Plan, as well as 12 females beyond the Recovery Zone boundary. Overall, population density declined along a north-south axis and toward the periphery of grizzly bear range (Fig. 5). Grizzly bears occupied $33,480 \mathrm{~km}^{2}$ in the NCDE during 19942007, including $10,340 \mathrm{~km}^{2}$ outside the Recovery Zone (Fig. 2A).

Factorial correspondence analysis identified 6 subpopulations in the NCDE (Fig. 2). In 4 of those subpopulations, genetic diversity approached levels found in undisturbed populations (15-locus mean $H_{E}=0.66-0.68$ ). However, genetic variability was lower in the eastern $\left(H_{E}=0.61\right)$ and southeastern $\left(H_{E}=0.62\right)$ subpopulations.

Despite the general absence of geographically delimited genetic discontinuities, genetic differentiation between the northern NCDE and the southern and eastern periphery $\left(F_{S T}=0.05-0.09 ; 16-118 \mathrm{~km}\right.$ apart $)$ was similar to or greater than the value $\left(F_{S T}=0.06\right)$ observed between the northern NCDE and the Prophet River population in British Columbia, Canada, 1,150 km to the north (Fig. 2B; Table 7; Poole et al. 2001). When we compared population structure for animals first captured 1976-1998 with that of animals first captured 1999-2006, we found that the genetic distinctiveness of the eastern and southwestern periphery decreased over time (Fig. 2).

The only signal of population fragmentation that aligned with landscape features was across Highway 2 and the BNSF rail line (Figs. 2, 6). There was little discernible genetic differentiation across the eastern portion of the corridor $\left(F_{S T}=0.01\right)$, but at the western end, where human density and traffic volumes were higher, differentiation indicated reduced genetic interchange $\left(F_{S T}=0.04\right.$; Fig. 6).

\section{DISCUSSION}

Our study provides the first ecosystem-wide status assessment of the NCDE grizzly bear population. Our abundance estimate was 2.5 times larger than the recovery program estimate. However, density varied dramatically; we found the highest concentrations of grizzly bears in Glacier National Park but detected fewer bears in the southern portion of the ecosystem. Our results suggested that the population was growing in terms of abundance, occupied habitat, and connectivity in areas of historically low genetic interchange. Our results also suggested that the population has generally remained genetically integrated and connected to Canadian populations. Conversely, we detected incipient fragmentation along the major transportation corridor in the NCDE and caution that continued unmitigated development may lead to reduced gene flow within this population and reduced connectivity to adjacent populations. Our use of 3 data sources increased our sample coverage, resulting in improved estimate precision and greater resolution of genetic population structure. We demonstrated that our NGS detected bears of all sex-age classes; therefore, our derived estimates reflect total population abundance. Our assessment suggests that grizzly bear recovery efforts have generally been successful; however, our results also highlight the need for improved monitoring techniques and reinforce the need to reduce the human-caused female mortality rate.

\section{Grizzly Bear Demography and Population Structure}

Abundance and mortality.-Our abundance estimate was more than double the existing estimate (Appendix) and represents the first ecosystem-wide estimate of this population to include a measure of precision. Although our estimate reflects the superpopulation abundance, given the low rates of bear movement off our study area, we felt 


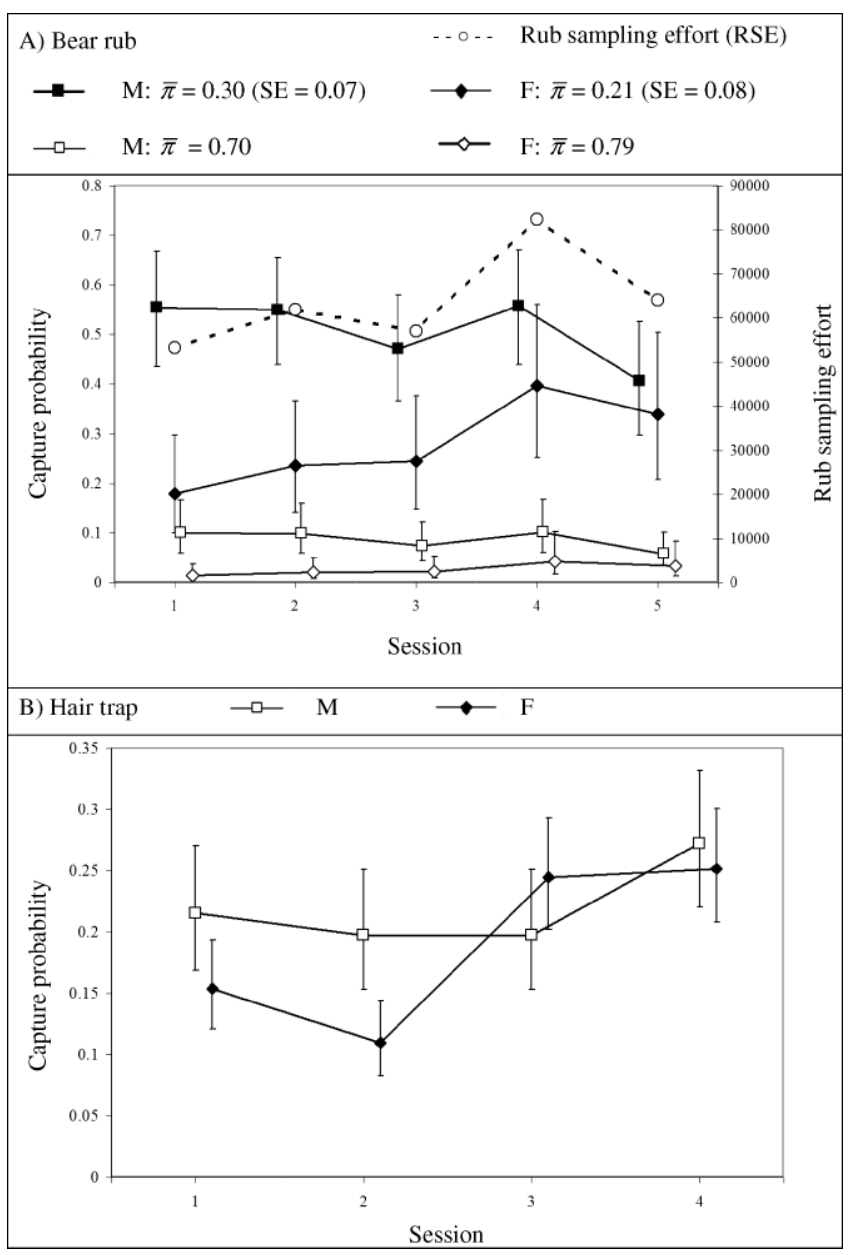

Figure 4. Gender-specific per session grizzly bear capture probability estimates from (A) bear rub surveys and (B) hair traps in the Northern Continental Divide Ecosystem, Montana, USA. Sampling sessions were 2 weeks long, beginning 15 June 2004. $\mathrm{Pi}(\pi)$ values represent the probability that an individual grizzly bear has 1 of 2 capture probabilities in the bear rub data. For example, in our data male bears had probability 0.30 of having the higher capture probabilities depicted in the top solid line. We derived estimates from the most selected models from Table 5. Rub sampling effort was the cumulative number of days between successive hair collections summed over all bear rubs sampled per session; values are presented on the secondary $y$ axis.

correcting for closure violation was unnecessary and would not impact inferences on population status. The known, human-caused mortality rate in 2004 when calculated with our abundance estimate was slightly above the $4 \%$ level considered sustainable (USFWS 1993). However, the number of mortalities in $2004(n=35)$ was the highest on record, and the female mortality rate was double the level allowed in the Recovery Plan. This is noteworthy because female survival is the most important driver of population trend (Schwartz et al. 2006). Although the Recovery Plan thresholds account for unreported mortality, this rate is difficult to measure and may vary over time (Cherry et al. 2002).

Knowing the sex-age classes included in population estimates is vital for monitoring population trend and making meaningful comparisons of density among populations. For example, dependent offspring can constitute 30\% of grizzly bear populations (Knight and Eberhardt 1985). Because an animal's age cannot be determined from hair, it has been unclear whether dependent offspring are sampled with hair snaring and included in abundance estimates derived from noninvasive sampling (Boulanger et al. 2004). Based on our large sample of bears $(n=276)$ for which sex and age were known, we found that hair snaring detected substantial proportions of the cubs and yearlings known to be present (Table 6). This represents the most conclusive evidence to date that bear population estimates derived from hair snaring include all sex-age classes. Our estimate of the DNA detection rate was likely conservative because 1) bears that have been previously live-captured may be less likely to be sampled in hair traps (Boulanger et al. 2008a); 2) some known bears may have ranged beyond the study area boundary during our sampling season, making them unavailable for DNA detection; and 3) unrecorded deaths could have occurred before DNA sampling.

Distribution.-Consistent with population expansion, we documented a substantial amount of habitat occupied by grizzlies beyond the Recovery Zone. Female grizzlies were well distributed and found in all bear management units. Although not all were of breeding age, the number and wide distribution of females detected suggest good reproductive potential. However, density varied substantially from high levels in Glacier National Park in the north to low levels in the south (Fig. 5). Several areas in the NCDE had few or no detections, including some that contained high-quality habitat, suggesting that there is still potential for population growth.

A single measure of bear density in a region as large and diverse as the NCDE would have little value and could be misleading compared with other populations. Climate, topography, vegetation, and land use were highly variable and likely influenced bear density patterns. Further complicating comparison with other populations, mammalian carnivore density estimates tend to vary inversely with study area size (Smallwood and Schonewald 1998).

Table 6. Number and proportion of grizzly bears that were present or potentially present that we detected with hair snaring in the Northern Continental Divide Ecosystem in northwestern Montana, USA, during the 2004 sampling period.

\begin{tabular}{|c|c|c|c|c|c|c|c|c|c|c|}
\hline & \multicolumn{2}{|c|}{$\mathrm{Cub}$} & \multicolumn{2}{|c|}{ Yearling } & \multicolumn{2}{|c|}{ Subadult } & \multicolumn{2}{|c|}{ Ad } & \multicolumn{2}{|c|}{ Total } \\
\hline & No. & $\%$ & No. & $\%$ & No. & $\%$ & No. & $\%$ & No. & $\%$ \\
\hline $\mathrm{F}$ & 11 & 36 & 7 & 100 & 11 & 55 & 118 & 89 & 147 & 83 \\
\hline M & 5 & 60 & 8 & 63 & 20 & 75 & 96 & 94 & 129 & 88 \\
\hline Total & 16 & 44 & 15 & 80 & 31 & 68 & 214 & 91 & 276 & 85 \\
\hline
\end{tabular}




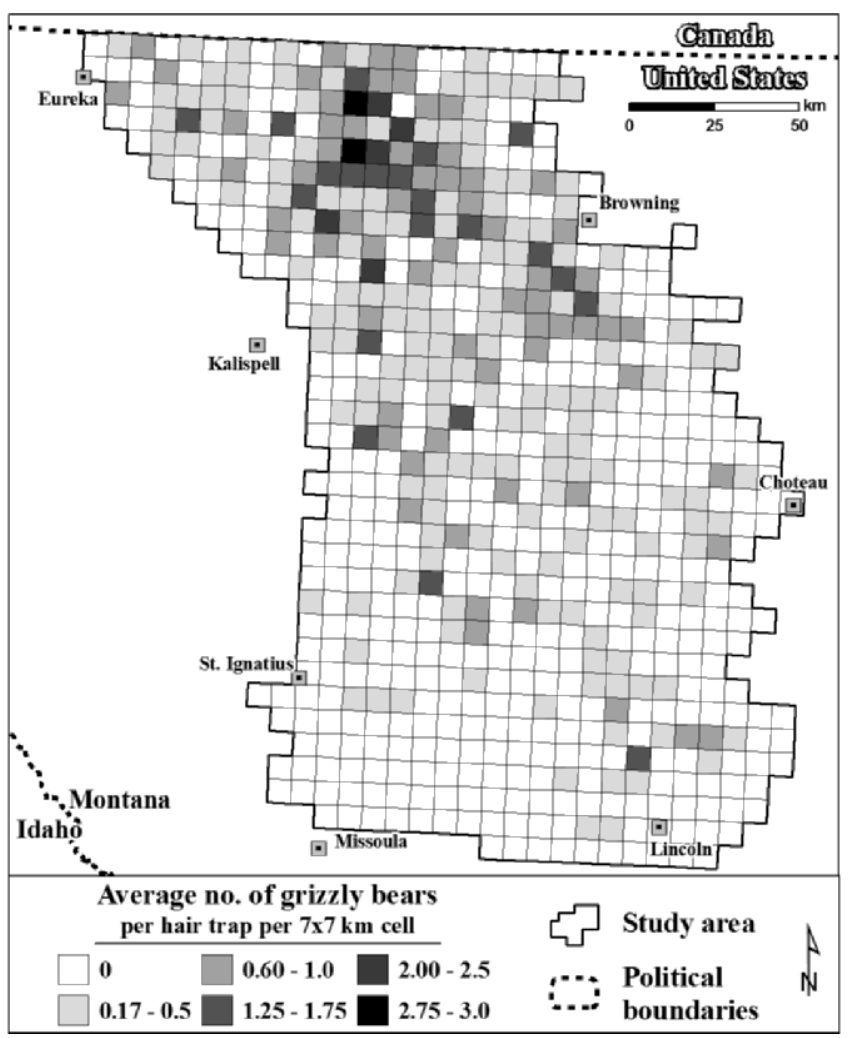

Figure 5. Relative density of grizzly bears in the $31,410-\mathrm{km}^{2}$ Northern Divide Grizzly Bear Project study area in northwestern Montana, USA. We conducted sampling 15 June-18 August 2004 at 2,558 hair traps systematically distributed on a $7 \times 7-\mathrm{km}$ grid. Because equal sampling effort was required for this analysis, we used only hair trap data.

Typically, larger study areas include more habitat heterogeneity, which is often associated with variation in animal abundance. Smaller areas include proportionally more animals with home ranges overlapping the study area boundary, which, if not corrected for, can result in positively biased abundance estimates (Miller et al. 1997, Boulanger and McLellan 2001). At $31,410 \mathrm{~km}^{2}$, our study area was much larger than those of most other terrestrial wildlife abundance estimation studies.

Population structure.-Genetic diversity in the NCDE approached levels seen in relatively undisturbed populations in northern Canada and Alaska, USA (Paetkau et al. 1998). Our results suggest that this population had not experienced a severe genetic bottleneck and that connectivity within the population and with the Canadian Rocky Mountain populations remained largely intact. The apparent recent increase in gene flow with the eastern periphery of the study area was consistent with population recovery. The historically low levels of genetic interchange and subsequently reduced diversity in the eastern and southeastern areas were similar to levels observed along the edges of the Canadian grizzly bear distribution and did not align with any landscape features (Proctor et al. 2005). However, our observation of reduced connectivity at the more developed western end of the dominant transportation corridor in the NCDE may signal the need for management intervention to ensure gene flow across this corridor in the future (Proctor et al. 2005).

\section{Data Sources, Analytical Methods, and Data Quality}

Supplemental data sources.-Having access to information such as mortality records, familial relationships, and animal movement data allowed us to investigate central assumptions of NGS studies. Some studies have assumed that juvenile bears are not sampled with hair snaring (e.g., Dreher et al. 2007). Our data showed that our abundance estimate based on hair snaring included all cohorts in the population. Noninvasive genetic sampling studies that assume juvenile bears are not vulnerable to sampling may overestimate total population abundance. In the absence of data on the detection rate of cubs and yearlings for individual study designs, our data argue for assuming that they are sampled. We also used management records to document partial independence of detection probabilities of family members traveling together, thus easing concern that a lack of independence among individuals creates bias in variance estimates.

The management and research records we gathered on grizzly bears in this ecosystem previously resided with individual researchers and wildlife managers from 8 agencies in dozens of locations in the United States and Canada. In addition to the assumptions investigated above, we used these data to 1) increase sample coverage, extend encounter histories, and improve the precision of our abundance estimate; 2) produce a comprehensive map of grizzly bear occupied habitat in the NCDE; and 3) document the apparent decrease in genetic differentiation among population segments over time. Management responsibility for

Table 7. Changes in genetic differentiation $\left(F_{S T}\right)$ between regions within the Northern Continental Divide Ecosystem (NCDE) grizzly bear population in northwestern Montana, USA. $F_{S T}$ values for 1976-1998 are below the diagonal; 1999-2006 values are above the diagonal. The Prophet River, British Columbia, Canada, grizzly bear population $1,150 \mathrm{~km}$ north of the NCDE was included for comparison with within-NCDE population distances. Only 2 genotypes were available for the southeast region before 1999.

\begin{tabular}{lcccccr}
\hline Region & Prophet & NW & NE & Mid & East & SW \\
\hline Prophet & & 0.07 & 0.07 & 0.05 & 0.10 & 0.09 \\
NW & 0.06 & & 0.02 & 0.02 & 0.08 & 0.06 \\
NE & 0.06 & 0.02 & & 0.02 & 0.07 & 0.05 \\
Mid & 0.05 & 0.02 & 0.01 & & 0.05 & 0.03 \\
East & 0.12 & 0.10 & 0.08 & 0.06 & & 0.05 \\
SW & 0.09 & 0.07 & 0.06 & 0.04 & 0.07 & 0.05 \\
SE & & & & & &
\end{tabular}




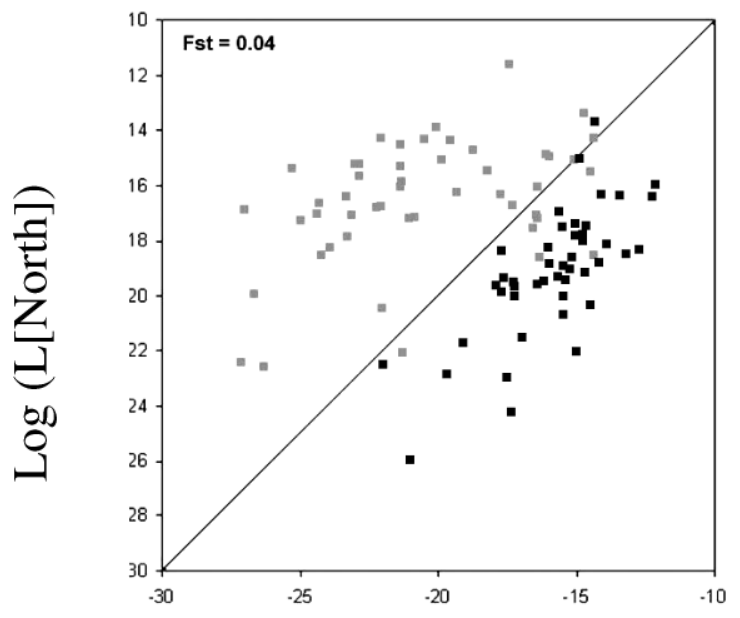

A

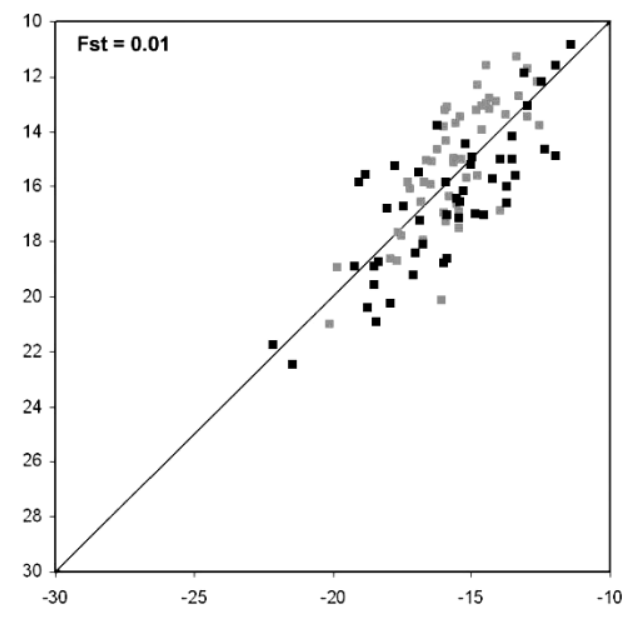

B

\section{$\log (\mathrm{L}[$ South $])$}

Figure 6. Genetic differentiation determined by assignment test between bears located on either side of the highway corridor for 2 segments of United States Highway 2, northwestern Montana, USA, 2004. Gray squares = bears north of highway; black squares = bears south of highway. (A) Western segment with higher traffic volume and human density. (B) Eastern segment with less traffic and development.

most populations of wide-ranging species is shared by multiple agencies. Centralized databases with standardized data and tissue sample repositories can be extremely useful and will become more valuable with time as analytical techniques are refined.

Mark-recapture methods.-Noninvasive genetic sampling has been widely used for estimating abundance of grizzly and black bear populations (Boulanger et al. 2002, Boersen et al. 2003), but estimates have often been imprecise ( $\mathrm{CV}>20 \%$; Boulanger et al. 2002) and thus of limited use for detecting trends or guiding management policy, such as setting harvest rates. Factors that contributed to the precision of our estimate $(\mathrm{CV}=3.8 \%)$ included the use of multiple sampling methods, the development of advanced mark-recapture modeling techniques (Boulanger et al. 2008a), and the large scale of our study. Combining detections from multiple data sources into single encounter histories yielded robust estimates with higher precision than a single-source approach (Boulanger et al. 2008a, Kendall et al. 2008). Mark-recapture models that can incorporate individual, group, and temporal covariates increase precision or reduce bias by more effectively modeling the heterogeneity in capture probabilities that is pervasive in wild populations (Huggins 1991, Pledger 2000, Boulanger et al. 2008a). Large study areas result in the larger sample sizes needed to model heterogeneity and reduce the effect of closure violation - a common source of capture probability variation. Our resulting population estimate was the most precise estimate obtained for a grizzly bear population using NGS.

Use of 3 sampling methods reduced estimate bias by increasing sample coverage; each method identified bears not sampled by the other methods (Table 8). Inclusion of physical capture data provided an opportunity to estimate capture probability for bears that were not detected using either hair snaring method and helped model heterogeneity in hair trap capture probabilities (Boulanger et al. 2008a, b).

An important assumption in mark-recapture analyses is the independence of capture probabilities among individuals. Family groups (parent-offspring and siblings traveling together) are the largest source of nonindependent movement in bear populations. Simulations suggested inclusion of dependent offspring causes minimal bias to population estimates but potentially a slight negative bias to variance estimates (Miller et al. 1997, Boulanger et al. 2004, Boulanger et al. 2008b). The magnitude of this phenomenon, however, has not been adequately explored with empirical data. Our evidence of partial independence of capture probabilities within family groups further suggested that this source of heterogeneity was unlikely to be a significant source of bias in our estimates.

Heterogeneity caused by lack of geographic closure is also a major challenge for DNA-based abundance estimation projects using closed models (Boulanger and McLellan 2001, Boulanger et al. 2004). The most effective ways to decrease this source of bias are to sample the entire

Table 8. Number and proportion of individual grizzly bears identified per sampling method during the Northern Divide Grizzly Bear Project, Montana, USA, 2004.

\begin{tabular}{|c|c|c|c|c|}
\hline \multirow[b]{2}{*}{ Sampling method } & \multicolumn{2}{|c|}{$\mathbf{M}$} & \multicolumn{2}{|c|}{$\mathbf{F}$} \\
\hline & No. & $\%$ & No. & $\%$ \\
\hline Hair trap only & 83 & 35 & 187 & 61 \\
\hline Bear rub only & 56 & 24 & 41 & 13 \\
\hline $\begin{array}{l}\text { Both noninvasive genetic } \\
\text { sampling (NGS) methods }\end{array}$ & 99 & 42 & 79 & 26 \\
\hline Handled bears ${ }^{\mathrm{a}}$ & 4 & 22 & 14 & 78 \\
\hline Total & 242 & 43 & 321 & 57 \\
\hline
\end{tabular}

${ }^{a}$ Of those bears detected in $\geq 1$ NGS methods, 31 (18 M, $13 \mathrm{~F}$ ) also had a record of physical capture. 
population or minimize the ratio of open edge to area sampled. We sampled essentially all occupied grizzly bear habitat associated with the NCDE in the United States and used telemetry data to assess movement rates across study area boundaries. We found extremely low levels of closure violation; therefore, we did not correct our estimate of abundance for lack of closure but used DTE to account for expected lower capture probabilities for bears along the northern edge of the study area.

Individual heterogeneity in capture probabilities is the most difficult problem facing the estimation of animal abundance (Link 2003, Lukacs and Burnham 2005b). The physical captures used in our encounter histories were not the result of even sampling effort across the study area. However, their inclusion may have reduced heterogeneityinduced bias resulting from unknown sources, such as behavioral traits or age, neither of which are known from DNA data and therefore cannot be modeled (Boulanger et al. 2008b). We included the PrevCap covariate in hair trap models because Boulanger et al. (2008b) found that detection probabilities at hair traps can be lower for bears that have been live-captured due to caution associated with similar lure and human scents. This effect was not expected at bear rubs because rubbing is a natural behavior with no association with human encounters; therefore, we did not consider the PrevCap covariate in bear rub models. We included terms to model the effects of gender-specific heterogeneity and gender-specific temporal trends in capture probabilities for both hair trap (Boulanger et al. 2004) and bear rubs (Kendall et al. 2008). Our results were similar to those of Kendall et al. (2008), who found increasing capture probabilities for females in both sampling methods in the northern portion of the NCDE. Males showed less consistency in temporal trends in capture probabilities across projects; however, males showed higher capture probabilities than females in bear rub data across all years of sampling. Our results suggest that sampling later in the season results in greater capture probabilities, especially for females, and should result in more precise abundance estimates.

Data quality.-Some researchers advocate modeling genotyping error rates in mark-recapture analyses (Lukacs and Burnham 2005a). However, we not only used a protocol that has been shown capable of reducing error rates to a trivial level (Paetkau 2003), we also went beyond that protocol to duplicate all genotypes, whether or not they were similar to another genotype, and to confirm the authenticity of all 563 identified individuals using an independent set of microsatellite markers. This provided strong evidence that no spurious individuals were created through undetected genotyping error. Our data do not rule out the possibility that we sampled 2 individuals with the same 7-locus genotype, but do demonstrate that such events were exceedingly uncommon, if they occurred at all. The estimated error rate for the number of individual bears identified through genotyping was $\leq 1 \%$. Errors of this magnitude do not bias mark-recapture population estimates, whereas addition of a parameter (error rate) to the population estimation model would reduce the precision of the estimate.

We used bar-coded sample numbers and scanners to help ensure that genetic results were associated with the correct field data by eliminating transcription and data entry errors in the field, office, and lab. We used data entry personnel with extensive experience in data quality control. Our database contained integrated error-checking queries that immediately identified questionable data and allowed us to resolve issues at the time of entry. We used GIS to verify the origin of samples, and we reviewed the detection history of each individual bear for inconsistencies. Furthermore, field crews received 9 days of training in protocols, project background, laboratory methods, bear ecology, GPS use, and other topics that contributed to successful execution of field duties. Our use of such rigorous quality control measures contributed to our confidence in our results.

\section{Monitoring Populations with Noninvasive Genetic Sampling}

Monitoring and recovery programs for threatened and endangered species are usually a compromise between the quality of data desired and the cost of obtaining it (Doak and Mills 1994, Miller et al. 2002) and are often woefully inadequate (Vucetich et al. 2006). Abundance estimates are the most common quantitative criterion in recovery plans (Gerber and Hatch 2002); however, they are often imprecise, error-ridden, or based on guesses (Holmes 2001, Campbell et al. 2002). In some cases, insufficient or erroneous data can directly influence how management efforts are prioritized and may result in misallocation of finite conservation resources (McKelvey et al. 2008). For example, inaccurate abundance estimates may result in misleading forecasts of population persistence because the magnitude of demographic stochasticity effects are a function of population size (Schwartz et al. 2006). Interpretation of per capita growth rate estimates may also be impacted by poor data, because growth rates can be affected by density-dependent demographic stochasticity (Drake 2005). For example, a monitoring program estimating trend would predict a flat or declining growth rate if the population was believed to be at or above carrying capacity $(K)$. However, with inaccurate estimates of $N$ or $K$, a declining growth rate could suggest that the population is experiencing a density-independent decline and elicit unnecessary management intervention.

To reliably monitor population trend, researchers must understand underlying patterns of variation in density and vital rates to guide stratified sampling, or sampling must be intensive enough to capture the variation. Measures of population trend such as those developed from projection matrices, commonly used for bears, may be insensitive to declines in some components of the population (Doak 1995). Using NGS methods for long-term monitoring therefore may be appealing when there is substantial heterogeneity in animal density and vital rates within a population, as with grizzly bears in the NCDE. Systematic 
NGS of the entire study area may be able to detect changes in local density (Fig. 5), patch occupancy, and genetic structure (Fig. 2), as well as ecosystem-wide abundance and apparent survival. Low intensity or periodic genetic sampling, such as with bear rub surveys, could be an efficient complement to, or more effective than, sightingand telemetry-based methods for monitoring dispersal, distribution, genetic structure, and population trend.

\section{MANAGEMENT IMPLICATIONS}

Our results indicate that the NCDE grizzly bear population is faring better than the USFWS monitoring program had indicated previously. However, it is likely that continued unmitigated development along the Highway 2 corridor will result in genetic fragmentation of the grizzly bear population in the NCDE. Increased traffic volume and development along the other highways in the NCDE carries similar risks. Any long-term management strategy for this population should include ways to facilitate continued genetic interchange across transportation corridors and the associated development that tends to grow along them.

The results of a 1-year study cannot measure population trend. Nonetheless, the recent decrease in genetic differentiation and apparent expanded distribution in the NCDE were consistent with population growth. In addition, the number and wide distribution of females we detected bodes well for the population. However, not all recovery criteria have been met. For example, even with our higher abundance estimate, the female mortality rate in 2004 was double the maximum allowed by the Recovery Plan. This suggests that, overall, management efforts have been effective in protecting this population but additional strategies are needed to reduce the female mortality rate, which is particularly important because the level of unreported mortality is difficult to assess. Clearly, a more intensive program should be considered to monitor population status and determine if mortality rates are sustainable. Based on our results, along with evidence of bear movement among populations and the recent initiation of a telemetry-based population trend study, the USFWS initiated a Status Review of threatened grizzly bear populations. This represents the first step in developing scientifically rigorous Recovery Plans for grizzly bears in the contiguous United States.

\section{ACKNOWLEDGMENTS}

W. Kendall and T. McDonald shared in developing our mark-recapture modeling approach. T. Graves assisted with model development and preliminary analyses. P. Cross, P. Lukacs, R. Mace, S. Miller, M. Schwartz, and an anonymous reviewer provided helpful comments on earlier drafts of this paper. We thank the hundreds of employees and volunteers who collected hair samples under difficult field conditions, entered reams of data, and processed thousands of hair samples. We also thank the following agencies that provided substantial logistical and in-kind support: Blackfeet Nation; Confederated Salish and Koote- nai Tribes; Montana Department of Fish, Wildlife, and Parks; Montana Department of Natural Resources and Conservation; National Park Service; Northwest Connections; United States Bureau of Land Management; USFWS; and the University of Montana. Outstanding leadership by C. Barbouletos and M. Long helped make this project possible. Financial support was provided by the United States Geological Survey and United States Forest Service.

\section{LITERATURE CITED}

Abbott, R. 2008. Pierre Taberlet Recipient of 2007 Molecular Ecology Prize (editorial). Molecular Ecology 17:514-515.

Andelman, S. J., and W. F. Fagan. 2000. Umbrellas and flagships: efficient conservation surrogates or expensive mistakes? Proceedings of the National Academy of Sciences USA 97:5954-5959.

Barluenga, M., K. N. Stolting, W. Salzburger, M. Muschick, and A. Meyer. 2006. Sympatric speciation in Nicaraguan Crater Lake cichlid fish. Nature 439:719-723.

Belkhir, K., P. Borsa, L. Chikhi, N. Rafaste, and F. Bonhomme. 2004. GENETIX 4.05, logiciel sous Windows TM pour la génétique des populations. Laboratoire Génome, Populations, Interactions, CNRS UMR 5000, Université de Montpellier II, Montpellier, France. < http:// www.genetix.univ-montp2.fr/genetix/genetix.htm>. Accessed $11 \mathrm{Apr}$ 2007.

Boersen, M. R., J. D. Clark, and T. L. King. 2003. Estimating black bear population density and genetic diversity at Tensas River, Louisiana using microsatellite DNA markers. Wildlife Society Bulletin 31:197-207.

Boulanger, J., K. C. Kendall, J. B. Stetz, D. A. Roon, L. P. Waits, and D. Paetkau. 2008a. Multiple data sources improve DNA-based markrecapture population estimates of grizzly bears. Ecological Applications 18:577-589.

Boulanger, J., and B. McLellan. 2001. Closure violation in DNA-based mark-recapture estimation of grizzly bear populations. Canadian Journal of Zoology 79:642-651.

Boulanger, J., B. N. McLellan, J. G. Woods, M. F. Proctor, and C. Strobeck. 2004. Sampling design and bias in DNA-based capture-markrecapture population and density estimates of grizzly bears. Journal of Wildlife Management 68:457-469.

Boulanger, J., G. C. White, B. N. McLellan, J. Woods, M. Proctor, and S. Himmer. 2002. A meta-analysis of grizzly bear DNA mark-recapture projects in British Columbia, Canada. Ursus 13:137-152.

Boulanger, J., G. C. White, M. Proctor, G. Stenhouse, G. Machutchon, and S. Himmer. 2008b. Use of occupancy models to estimate the influence of previous live captures on DNA-based detection probabilities of grizzly bears. Journal of Wildlife Management 72:589-595.

Burnham, K. P., and D. R. Anderson. 2002. Model selection and multimodel inference: a practical information-theoretic approach. Springer-Verlag, New York, New York, USA.

Campbell, S. P., J. A. Clark, L. H. Crampton, A. D. Guerry, L. T. Hatch, P. R. Hosseini, J. J. Lawler, and R. J. O'Connor. 2002. An assessment of monitoring efforts in endangered species recovery plans. Ecological Applications 12:674-681.

Cardillo, M., G. M. Mace, K. E. Jones, J. Bielby, O. R. P. BinindaEmonds, W. Sechrest, C. D. Orme, and A. Purvis. 2005. Multiple causes of high extinction risk in large mammal species. Science 309:1239-1241.

Cherry, S., M. A. Haroldson, J. Ronbison-Cox, and C. C. Schwartz. 2002. Estimating total human-caused mortality from reported mortality using data from radio-instrumented grizzly bears. Ursus 13:175-184.

Crosbie, S. F., and B. F. J. Manly. 1985. Parsimonious modeling of capture-mark-recapture studies. Biometrics 41:385-398.

Doak, D. F. 1995. Source-sink models and the problem of habitat degradation: general models and applications to the Yellowstone grizzly. Conservation Biology 9:1370-1379.

Doak, D. F., and L. S. Mills. 1994. A useful role for theory in conservation. Ecology 75:615-626.

Drake, J. M. 2005. Density-dependent demographic variation determines extinction rate of experimental populations. PLoS Biology 3:1300-1304. 
Dreher, B. P., S. R. Winterstein, K. T. Scribner, P. M. Lukacs, D. R. Etter, G. J. M. Rosa, V. A. Lopez, S. Libants, and K. B. Filcek. 2007. Noninvasive estimation of black bear abundance incorporating genotyping errors and harvested bears. Journal of Wildlife Management 71:26842693.

Ennis, S., and T. F. Gallagher. 1994. PCR based sex determination assay in cattle based on the bovine Amelogenin locus. Animal Genetics 25:425427.

Fitch, W. M., and E. Margoliash. 1967. Construction of phylogenetic trees. Science 155:279-284.

Gerber, L. R., and L. T. Hatch. 2002. Are we recovering? An evaluation of recovery criteria under the U.S. Endangered Species Act. Ecological Applications 12:668-673.

Gibbons, A. 1992. Mission impossible: saving all endangered species. Science 256:1386.

Gittleman, J. L., and M. E. Gompper. 2001. Ecology and evolution. The risk of extinction — what you don't know will hurt you. Science 291:997998.

Holmes, E. E. 2001. Estimating risks in declining populations with poor data. Proceedings of the National Academy of Sciences USA 98:50725077.

Huggins, R. M. 1991. Some practical aspects of a conditional likelihood approach to capture experiments. Biometrics 47:725-732.

Kadwell, M., M. Fernanadez, H. F. Stanley, R. Baldi, J. C. Wheeler, R. Rosadio, and M. W. Bruford. 2001. Genetic analysis reveals the wild ancestors of the llama and the alpaca. Proceedings of the Royal Society, London B 268:2575-2584.

Kendall, K. C., J. B. Stetz, D. A. Roon, L. P. Waits, J. B. Boulanger, and D. Paetkau. 2008. Grizzly Bear Density in Glacier National Park, Montana. Journal of Wildlife Management 72:1693-1705.

Knight, R. R., and L. L. Eberhardt. 1985. Population dynamics of Yellowstone grizzly bears. Ecology 66:323-334.

Link, W. A. 2003. Nonidentifiability of population size from capturerecapture data with heterogeneous detection probabilities. Biometrics 59: 1123-1130.

Lukacs, P. M., and K. P. Burnham. 2005a. Estimating population size from DNA-based closed capture-recapture data incorporating genotyping error. Journal of Wildlife Management 69:396-403.

Lukacs, P. M., and K. P. Burnham. 2005b. Review of capture-recapture methods applicable to noninvasive genetic sampling. Molecular Ecology 14:3909-3919.

McKelvey, K. S., K. B. Aubrey, and M. K. Schwartz. 2008. Using anecdotal occurrence data for rare or elusive species: the illusion of reality and a call for evidentiary standards. BioScience 58:549-555.

Miller, J. M. C., M. Scott, C. R. Miller, and L. P. Waits. 2002. Endangered Species Act: dollars and sense? BioScience 52:163-168.

Miller, S. D., G. C. White, R. A. Sellers, H. V. Reynolds, J. W. Schoen, K. Titus, V. G. Barnes, Jr., R. B. Smith, R. R. Nelson, W. B. Ballard, and C. C. Schwartz. 1997. Brown and black bear density estimation in Alaska using radiotelemetry and replicated mark-resight techniques. Wildlife Monographs 133

Mills, L. S., J. J. Citta, K. P. Lair, M. K. Schwartz, and D. A. Tallmon. 2000. Estimating animal abundance using noninvasive DNA sampling: promise and pitfalls. Ecological Applications 10:283-294.
Paetkau, D. 2003. An empirical exploration of data quality in DNA-based population inventories. Molecular Ecology 12:1375-1387.

Paetkau, D., W. Calvert, I. Stirling, and C. Strobeck. 1995. Microsatellite analysis of population structure in Canadian polar bears. Molecular Ecology 4:347-354.

Paetkau, D., L. P. Waits, P. L. Clarkson, L. Craighead, E. Vyse, R. Ward, and C. Strobeck. 1998. Variation in genetic diversity across the range of North American brown bears. Conservation Biology 12:418-429.

Pledger, S. 2000. Unified maximum likelihood estimates for closed capturerecapture models using mixtures. Biometrics 56:434-442.

Poole, K. G., G. Mowat, and D. A. Fear. 2001. DNA-based population estimate for grizzly bears Ursus arctos in northeastern British Columbia, Canada. Wildlife Biology 7:105-115.

Proctor, M. F., B. N. McLellan, C. Strobeck, and R. M. R. Barclay. 2005. Genetic analysis reveals demographic fragmentation of grizzly bears yielding vulnerably small populations. Proceedings of the Royal Society Biology 272:2409-2416.

Roon, D. A., L. P. Waits, and K. C. Kendall. 2005. A simulation test of the effectiveness of several methods for error-checking non-invasive genetic data. Animal Conservation 8:203-215.

Schonewald-Cox, C., R. Azari, and S. Blume. 1991. Scale, variable density, and conservation planning for mammalian carnivores. Conservation Biology 5:491-495.

Schwartz, C. C., M. A. Haroldson, G. C. White, R. B. Harris, S. Cherry, K. A. Keating, D. Moody, and C. Servheen. 2006. Temporal, spatial, and environmental influences on the demographics of grizzly bears in the Greater Yellowstone Ecosystem. Wildlife Monographs 161.

Smallwood, K. S., and C. Schonewald. 1998. Study design and interpretation of mammalian carnivore density estimates. Oecologia 113:474-491.

Taberlet, P., S. Griffin, B. Goossens, S. Questiau, V. Manceau, N. Escaravage, L. P. Waits, and J. Bouvet. 1996. Reliable genotyping of samples with very low DNA quantities using PCR. Nucleic Acids Research 24:3189-3194.

U.S. Fish and Wildlife Service [USFWS]. 1993. Grizzly Bear Recovery Plan. U.S. Fish and Wildlife Service, Missoula, Montana, USA.

Vucetich, J. A., M. P. Nelson, and M. K. Phillips. 2006. The normative dimension and legal meaning of endangered and recovery in the U.S. Endangered Species Act. Conservation Biology 20:1383-1390.

Weir, P. S., and C. C. Cockerham. 1984. Estimating F-statistics for the analysis of population structure. Evolution 38:1358-1370.

White, G. C., and K. P. Burnham. 1999. Program MARK: survival estimation from populations of marked animals. Bird Study Supplement 46:120-138.

White, G. C., K. P. Burnham, and D. R. Anderson. 2001. Advanced features of Program Mark. Pages 368-377 in R. Field, R. J. Warren, H. Okarma, and P. R. Sievert, editors. Wildlife, land, and people: priorities for the 21st century. Proceedings of the second international wildlife management congress. The Wildlife Society, Bethesda, Maryland, USA.

Woods, J. G., D. Paetkau, D. Lewis, B. N. McLellan, M. Proctor, and C. Strobeck. 1999. Genetic tagging of free-ranging black and brown bears. Wildlife Society Bulletin 27:616-627.

Associate Editor: McCorquodale. 


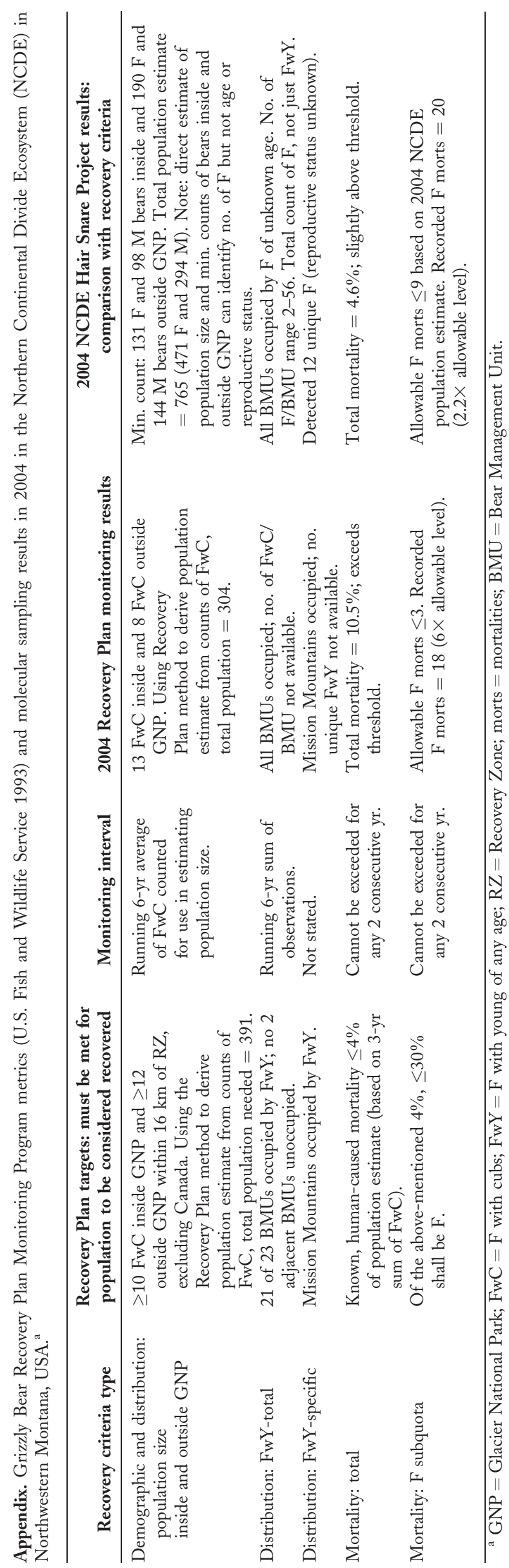

